\title{
Weaving Teaching and Leading: A Systematic Literature Review on Pedagogical Leadership Contributions
}

\author{
Manuel E.Caingcoy \\ Professional Studies Department \\ College of Education, Bukidnon State University \\ Malaybalay City, Bukidnon, Philippines
}

\begin{abstract}
Pedagogical leadership has become an emerging and essential debate in the field of educational administration and leadership. This was a result of the shift from the hierarchical type in the past to a more inclusive, collaborative, and participative leadership. Previous studies indicate the furtherance of the inquiry into pedagogical leadership since it is a work in progress. Method: For this reason, a systematic literature review mapped the literature relevant to pedagogical leadership. Findings: The review drew the lines between the empirical and theoretical-conceptual contributions, including the methodologies considered in both contributions. Implications for Research and Practice: The results have implications for a more robust theoretical-empirical model or framework of pedagogical leadership applicable to specific levels of education, especially higher education contexts. The study also implies applying pedagogical leadership in the team, at departmental and organizational levels. Results imply promoting the culture of pedagogical leadership.
\end{abstract}

Keywords:- Empirical, Conceptual and Theoretical Contributions, Methodologies.

\section{INTRODUCTION}

Pedagogical leadership has become an emerging debate in the field of educational administration and leadership. Since its inception, there have been increasing empirical studies (Fonsén et al., 2020; Heikka et al., 2019a; Heikka et al., 2019b; Martinez et al., 2018a; Lee, 2016; Male et al., 2016; Brandon et al., 2016), critical and systematic reviews (MacNeill et al., 2005; Martinez et al., 2018b; Peng et al., 2016; Contreras, 2016), and books about it (Semann, 2019; Fonsen, 2013; Andrews, 2009) have attempted to contribute to this debate. Much of the contributions are in the field of Early Childhood Education (Fonsén et al., 2020; Clarke, 2017; Abel, 2016; Atkinson et al., 2017; Heikka et al., 2019a; Heikka, 2014; Heikka et al., 2011; Cecchin et al., 2009). These studies show an engendered interest in pedagogical leadership (Andrews, 2009).

In a critical review, MacNeill et al. (2005) compared the instructional and pedagogical leadership, which highlights the limitations of the former and the advantages of the latter. Accordingly, the former is just a parcel of the latter. Pedagogical leadership is more inclusive in improving learning organizations (Abel, 2016). This was the reason why scholars, especially ECE educators and leaders, have shifted their attention to it. This new leadership was introduced as an alternative to instructional and all other leadership (Male et al., 2012; Atkinson et al., 2017; MacNeill et al., 2005). Male et al. (2015) also recommended a shift based on their findings. This leadership is not limited to those who have ranks and formal positions in the organization. In the words of Sergiovanni (1998), pedagogical leadership:

Invests in capacity building by developing social and academic capital for students and intellectual and professional capital for teachers. Support this leadership by making capital available to enhance student learning and development, teacher learning, and classroom effectiveness. (p. 38).

Coughlin et al. (2013) introduced four principles of pedagogical leadership. These are the use of the protocol to support reflective thinking and inquiry, set up professional learning communities, and allow time and parallel practices. On the other hand, Brandon et al. (2016) support some principles through their five strands of pedagogical leadership teaming: effective teaching, shared instructional leadership, professional learning, evidence, relational trust, and reflective discourse. However, Aung's (2018) exploratory appreciative inquiry reported that high school principals focused on the development of the whole child as the primary responsibility, that is, to attend to both academic and non-academic formation, while staff development is a secondary concern. It also claimed that a supportive school community can allow them to fulfill both primary and secondary focuses. In this, there are imbalances in the inception of pedagogical leadership indicated in the priorities of school principals.

Some studies did not have a clear conceptualization of pedagogical leadership (Martinez \& Tadeu, 2018a). A review recommended developing a questionnaire on distributed leadership (Martinez et al., 2018b). The same review has failed to come up with both a comprehensive and contextualized conceptual framework for pedagogical leadership. Moreover, the pedagogical leadership has conflicting conceptualizations and is frequently it was associated with someone who is an expert who dictates quality and suggests fixed ways of doing things (Atkinson et 
al., 2017; Muray, et al., 2013; Woodrow et al., 2009). Further, they said, "pedagogical leadership carries conflicting conceptualization..." (Atkinson, et al., 2017, p. 4). This alone is a major concern that needs further attention to provide a more succinct conceptualization or in theorizing this leadership.

Previous studies admitted that pedagogical leadership as a phenomenon has no definite definition (Fonsén et al., 2020), and it has limited theoretical advancement (Heikka et al., 2011; Heikka, 2014). Male et al. (2015) posited that the "construct of pedagogical leadership is a work in progress" (p. 229). This implies to further inquiry to produce a more robust underpinning of this new leadership. With the aforementioned, a review was carried out to track the scientific and scholarly contributions in theorizing and conceptualizing pedagogical leadership and to determine how these contributions have been derived. This review identified prospects for future research. To some extent, this paper adds value to the on-going conversation and the adoption of pedagogical leadership in teams, departments, and the whole school.

\section{METHODS}

This paper employed the thematic approach of a systematic literature review. This type of review provides a "systematic, transparent means for gathering, synthesizing, and appraising findings on a particular topic or question. The aim is to minimize the bias with single studies and nonsystematic reviews" (Sweet et al., 2007, p.1). This is not the usual section of a thesis or dissertation. Moreover, "a thematic analysis involves creating summaries of prominent and recurrent themes in the articles in a systematic way" (Gaogoses \& Koglin, 2020, p. 154). The following steps were undertaken: (1) searching for literature. It searched literature from Google and Educational Research Information Center (ERIC) using the keywords such as "Studies on Pedagogical Leadership + pdf", "Models of Pedagogical Leadership", "Empirical Evidence of Pedagogical Leadership". Step 2: screening and selecting literature from the results. At this level, online articles are downloaded, screened, and kept in the same folders. In selecting articles, the title must bear the keywords pedagogical leadership. The review covered all scholarly, open access, and relevant literature regardless of the year of publication. Step 3: evaluating selected literature using inclusion and exclusion criteria. Each article must be published in open access, reputable and peer-reviewed journals. Theses and dissertations were included. This literature can be empirical or theoretical articles. The former refers to studies that have been conducted in the field with primary data or source of information, while the latter entails articles that have been published using secondary data and these studies become data of theoretical papers like reviews and meta-analyses. The bibliography of the articles that passed the criteria was subjected to scrutiny. Again, using the same criteria, the literature listed in there were vetted and selected as long as the titles bear similar keywords. Step 4: extracting data. At this step, the researcher extracts statements, information, or excerpts from each article. In this stage, reading was done repeatedly, especially in identifying the contribution of the study to the body of knowledge on pedagogical leadership. In doing this, it allowed the researcher to group the common and differences, identify patterns, and the quality of the contribution and its methodology. This last stage was done iteratively until such time themes were derived. Step 5: synthesizing information. Here, a thorough discussion is provided based on the themes. The synthesis is reiterated in the conclusion by presenting again the salient points of the review.

\section{RESULTS}

The search of literature at Google and the Educational Research Information Center (ERIC) obtained the result of 29, 000, 000, and 10, 972, respectively. From these numbers, the study selected those articles that bear these words "pedagogical leadership." Initially, 45 studies were chosen in the screening. Using the inclusion and exclusion criteria for appraisal, only 17 articles qualified from Google and 2 from ERIC. This paper reviewed 19 scientific and peer-reviewed articles from reputable journals. The discussion of the results was guided by three themes: empirical contributions, theoretical-conceptual contributions, and methodologies in previous studies. The presentation of the contributions was done chronologically.

\section{DISCUSSION}

\section{A. Empirical Contributions}

These contributions were derived from studies with primary data gathered from the field through interviews, focus group discussions, documents, photos, observations, survey questionnaires, among others. Heikka (2013) investigated how municipal ECE leaders, center directors, and teachers perceive the enactment of pedagogical leadership. Pedagogical leadership was linked to stakeholders' positions and was associated with the center directors' tasks and responsibilities. It was linked limitedly to teachers and municipal ECE leaders' responsibilities. These perceptions of stakeholders' enactment of pedagogical leadership responsibilities indicate a limited knowledge and understanding of the topic of the investigation. This implies professional development among stakeholders for better understanding and eventually they can create an interdependent enactment of their respective responsibilities. In another study by Heikka (2014), she added municipal education committee members. Pedagogical leadership was perceived as the main leadership responsibility of all ECE stakeholders. However, there was insufficient sharing of pedagogical leadership responsibilities, and the center directors faced difficulties in sharing pedagogical improvement with teachers. Fortunately, there were signs of emerging construction of leadership as being distributed. It is understood as distributed since the study was conceptualized from the lens of the distributed leadership model. 
Alameen, Male, and Palaiologou (2015) validated the internal and external axes of the pedagogical leadership of Male and Palaiologou (2012). The values, beliefs, religion, customs, and local economy constitute the internal axis, while the societal values, global economy, mass media, social networking, ICT, national curriculum, and test scores of students comprised the external axis. The study has found evidence that formal leaders correspond their behaviors to internal pedagogical axes, rather than being solely driven by external agendas. Male and Palaiologou (2015) examined transformational, learner-centered, distributed, and situational models of leadership. The phrase "pedagogical leadership" appeared frequently across models in the literature. In some sources, it was referred to as a form of practice that shaped the weaving of teaching and leadership. They argued the ambiguity of attaching the term pedagogy to leadership. They indicate that vagueness needs further investigation. In their paper, praxis was the locus of this new leadership which is concerned with the integrated conceptualization of the relations among teaching and the learning ecology of the community. Male and Palaiologou (2016) continued their journeys for this alternative leadership. Their in-depth qualitative research generated three primary categories which include context, intervention strategies, and sustaining and extending the improvement process. The last category has six sub-themes: establishing a successful culture, managing external expectations, selection and induction of staff, managing a robust supportive environment, sustaining effective internal relationships, and head teacher leadership behaviors.

Brandon, Saar, Friesen, Brown, and Yee (2016) introduced the idea of pedagogical leadership teams. This is an emerging image of pedagogical leadership that can serve as a foundation of inquiry that seeks ways of expanding the impact PL in strengthening teaching and leadership practices that would improve student engagement, academic achievement, and well-being. This study contributed to coming up with five strands of teaming for this leadership. These are effective teaching; shared instructional leadership; professional learning; evidence, relational trust, and reflective discourse; and learning-focused district leadership.

For Lee (2016), pedagogical leadership is focused on teachers' growth. Accordingly, PL can significantly impact teachers' professional growth and practicing it allows teachers to adapt smoothly to the profession, reduce their stress, and stimulate their profession. In addition, Lee claimed that understanding teachers' emotions can result in adaptation to the new environment, considerable stress, feel responsible for their work, and increase their passion for profession and work. The study emphasized structured and non-structured support for teachers. Understanding teachers' challenges can be done by teaching and guiding them, exposing them to non-teaching tasks, and ensuring better work relations. Lee (2016) contributed to the debate the three dimensions of PL such as understanding new teachers, providing systematic support, and fostering supportive school culture.
Clarke (2017) brings into the debate the idea of sustainable pedagogical leadership and practices. These practices revealed a range of ethical inspiration in working together with a clear vision, engaging educators through constant mentoring and critical reflection, and empowering them by providing professional learning opportunities. Another literature promotes the type of pedagogical leadership that is dialogic, relational, and informed lived experiences. The relationship is manifested in a push and pull of ideas. PL allows people to be uncertain, which flattened the hierarchy type of leadership relations. In this PL, educators recognized dialogue, experimentation, and dissensus (Atkinson \& Biegun, 2017). Atkinson et al. (2017) reimagined $\mathrm{PL}$ as situated and collaborative.

Earlier, some studies on PL were focused on teachers. In Aung (2018), the principals have emphasized the three partakers (students, teachers, and community) in developing leadership experiences. In this appreciative inquiry, the primary focus of pedagogical leadership was on whole child development by attending both academic and non-academic formation of learners. Secondarily, PL focused on staff development. Lastly, the community was the last focus as support for the first two emphases. In a cross-sectional study, Martinez and Tadeu (2018a) noted the positive trends in the construction of a common educational project. The positive predisposition among staff to be involved in school initiatives toward collaboration and coordination among colleagues.

Heikka et al. (2019b) emphasized the interdependence of enacting leadership responsibilities. This interdependence is reflected in a clear strategy for distributed pedagogical leadership. In this image PL, teachers played an active role in leading pedagogical development within teams. This study contributed five functions of distributed pedagogical leadership: these include: constructing shared vision, goals and values for Early Childhood Education; developing the ECE center's pedagogy; facilitating learning and expertise of educators; developing the operational structures and cultures of the center; and enhancing participative and efficient decision-making. Heikka et al. (2019a) indicated that ECE centers adopted leadership approaches congruent with distributed pedagogical leadership. They implemented different forms of distributed leadership, which positively related to ECE teachers' ability to lead reflection and leaning in their teams. The study showed a high level of commitment among teachers to pedagogical leadership.

In Fonsén and Soukainen (2020), having a high professional status and being highly qualified can enhance the ability of the professionals to reflect critically pedagogical leadership and have more demanding attitudes toward the quality of pedagogical leadership. This study had six themes considered in the survey: leadership organization; human resource management; structure of the organization; pedagogic leadership; knowledge management and work well-being; and leadership of self. This paper argues that pedagogical leadership requires a sustainable structure. 


\section{B. Theoretical and Conceptual Contributions}

Some studies on pedagogical leadership were theoretically, conceptually derived or both. The theoretical contributions include studies that have been conducted through a systematic literature review, while the conceptual contributions are critical analysis and critiques. The former used secondary data from previous studies, while the latter is plainly analytical without the use of results of previous studies or empirical evidence.

Martinez et al. (2018b) reviewed 16 articles and found that most of the research in the review have found positive leadership effects on teacher professionalism, teaching and learning process, and student performance. Peng and Vašt'atková(2016) reported in their paper that those effective pedagogical leaders sustain a high level of pedagogical leadership by establishing trust, creating structures that promote teachers' learning. As found, many of the head teachers need to involve all stakeholders and draw them into the implementation process of pedagogical leadership and effectively build their capacity to take on new roles and responsibilities. It was also noted that headteachers need to be mindful of the shared norms and values before initiating new practices in a school. Peng et al. (2016) highlighted the core responsibilities of pedagogical leaders. These are supporting and developing teacher teaching and learning; self-development; creating and maintaining a supportive atmosphere of trust, and direct-setting and motivating others.

It was contended that pedagogical leaders need to be good communicators, risk-takers, truthful, insightful, facilitators, ideologists, inspiring [inspirers], have a broad vision and recognize good efforts (Butt, 2017). Contreras' (2016) review associated pedagogical leadership with school improvement and teaching leadership. In PL, the school was perceived comprehensively to serve the learners and their earning processes. This review noted that pedagogical leadership is both participative and distributed.

\section{Methodologies in Previous Studies}

The essential question is whether or not the contributions were derived from qualitative or quantitative research or in combination. To address this question, a methodological analysis is performed. Among the empirical literature on pedagogical leadership, most of the research designs and approaches used were qualitative (Heikka et al., 2019b; Aung, 2018; Atkinson et al., 2017; Clarke, 2017; Lee, 2016; Brandon et al., 2016; Male et al., 2016; Male et al., 2015), Alameen et al., 2015; Heikka, 2014; Heikka, 2013). There have been limited studies with quantitative designs (Fonsén et al., 2020; Martinez et al., 2018a) and explanatory sequential mixed methods design (Heikka et al., 2019a). Pedagogical leadership contributions were the results of descriptive (Fonsén et al., 2020; Martinez et al., 2018a), cross-sectional (Martinez et al., 2018a), appreciative inquiry (Aung, 2018), historical case
(Clarke, 2017), and case study methods (Lee, 2016; Brandon et al., 2016; Male et al., 2016), and interpretiveinductive methods (Alameen et al., 2015).

The most common data collection methods were interviews (Heikka et al., 2019a; Heikka et al., 2019b; Aung, 2018; Clarke, 2017; Lee, 2016), Male et al., 2016), Male et al., 2015), Alameen et al., 2015), focus group discussions (Heikka, 2014; Heikka, 2013; Male et al., 2016), documents (Heikka et al., 2019b; Clarke, 2017; Male et al., 2016), social media page and photographs (Clarke, 2017), and field notes (Alameen et al., 2015). Data in empirical contributions were analyzed using descriptive statistics (Fonsén et al., 2020; Heikka et al., 2019a; Martinez et al., 2018a), inferential statistics ((Heikka et al., 2019a; Martinez et al., 2018a), content (Heikka et al., 2019b; Lee, 2016; Male et al., 2015; Heikka, 2014; Heikka, 2013), narrative (Aung, 2018), thematic analysis (Clarke, 2017; Male et al., 2016), and interpretive (Alameen et al., 2015).

\section{CONCLUSION}

The weaving of constructs in pedagogical leadership was not limited between teaching and leading. One thing is certain, pedagogical leadership sprung from distributed, participative, and situated types of leadership. In the context of Early Childhood Education, this construct has been associated with the concept of sustainability. The literature had varied trajectories and focused either on teaching staff, students, or community. Most of the contributions to the development of pedagogical leadership culture were empirical. This implies that PL was developed through interviews and focus group discussions with the practitioners. Thus, there is a need to conduct a construct validation of pedagogical leadership using structural equation modeling or at least an exploratory factor analysis in the context of higher education, junior high school, and senior high school levels. This is to come up with more robust and encompassing dimensions of pedagogical leadership. There is a need for a more comprehensive and in-depth analysis of the overlapping theoretical underpinnings among distributed, participative, situated, and pedagogical leadership. There is also a need for more extensive systematic literature reviews on PL. In conducting research on this topic, it is advisable to try those methodologies that were limited in the literature. The results have implications for the furtherance of practicing pedagogical leadership and documenting best practices that support strong and productive collaboration among stakeholders. The results also imply advocating pedagogical leadership in the field.

\section{ACKNOWLEDGMENT}

A special thanks to authors of articles covered in this review as well as to Google, Google Scholar and ERIC. 


\section{REFERENCES}

[1]. Abel, M. (2016). Why Pedagogical Leadership? McCormick Center for Early Childhood Leadership. https://bit.ly/2UmqSNX

[2]. Alameen, L., Male, T., \& Palaiologou, I. (2015) Exploring Pedagogical Leadership in Early Years Education in Saudi Arabia. School Leadership and Management, 35(2). https://bit.ly/3dzk9bc 121-139. DOI: $10.1080 / 13632434.2014 .992773$

[3]. Alshanqiti, L. A. (2018). A Qualitative Study of Leadership in Saudi Arabian Early Childhood Education: Influential Factors and Critical Challenges(Dissertation). Canterbury Christ Church University. https://bit.ly/2UJkCPB

[4]. Andrews, M. (2009). Managing change and pedagogical leadership. In A. Robins and S. Callan (Eds.). Managing early years settings. Supporting and leading teams. London: SAGE, 45-64.

[5]. Atkinson, K., \& Biegun, L. (2017). An Uncertain Tale: Alternative Conceptualizations of Pedagogical Leadership. Journal of Childhood Studies, 42(4), 6168. https://bit.ly/3dNodou

[6]. Aung, T. (2018). Pedagogical Leadership in Myanmar: An Exploratory Study (Master's Thesis). Yangon University of Education, Myanmar. https://bit.ly/33OuQSG

[7]. Bolden, R. (2011). Distributed Leadership in Organizations: A Review of Theory and Research. International Journal of Management Reviews, 13, 251-269. https://bit.ly/2Jn9anu

[8]. Brandon, J., Saar, C., Friesen, S., Brown, B., \& Yee, D. (2016). Pedagogical Leadership Teams: Magnifying and Spreading Impact. IDEAS Conference. PRISM: University of Calgary's Digital Repository. https://bit.ly/2JmbATo

[9]. Butt, M. I. (2017). Principal, as a Pedagogical Leader: In the Perspective of Good Governance in the Public Sector Colleges of Pakistan. International Journal of Management and Applied Science, 3(3), 81-84. https://bit.ly/2UlAA3m

[10]. Cecchin, D., \& Johansen, M. W. (2009). Integrating leadership and pedagogy in early childhood institutions professional pedagogical leadership. Paper presented in the European Early Childhood Education Research Association Conference, Strasburg.

[11]. Clarke, J. (2017). Sustainable Pedagogical Leadership in Early Childhood Education and care: Implementing the 2012 Australian National Quality Standard (Master's Thesis). Queensland University of Technology. https://bit.ly/3bsAdcX

[12]. Contreras, T. S. (2016). Pedagogical Leadership, Teaching Leadership and their Role in School Improvement: A Theoretical Approach. Propósitos y Representaciones, 4(2), 231-284. https://bit.ly/2JjClaX

[13]. Coughlin, A. M., \& Baird, L. (2013). Pedagogical Leadership. London Bridge Child Care Services \& Kawartha Child Care Services. https://bit.ly/3btmMcM.
[14]. Fonsén, E., \& Soukainen, U. (2020). Sustainable Pedagogical Leadership in Finnish Early Childhood Education (ECE): An Evaluation by ECE Professionals. Early Childhood Education Journal, 48, 213-222. https://bit.ly/2xqo6P1

[15]. Fonsen, E. (2013). Dimensions of pedagogical leadership in early childhood education and care. In E. Hujala, M. Waniganayake, \& J. Rodd (Eds.), Researching Leadership in Early Childhood Education (pp. 181-192). [11] Tampere: Tampereen yliopistopaino.

[16]. Gaogoses, N., \& Koglin, U. (2020). The Role of Social Goals in Academic Success: Recounting the Process of Conducting Systematic Literature Review. In Ritcher, O. Z., Kerres, M., Bedenlier, S., Bond, M., \& Buntins, K. (Eds.). (2020). Systematic Reviews in Educational Research: Methodology, Perspectives and Application. Springer VS. https://bit.ly/2JowOQz

[17]. Heikka, J., Pitkäniemi, H., Kettukangas, T., \& Hyttinen, T. (2019a). Distributed pedagogical leadership and teacher leadership in early childhood education contexts. International Journal of Leadership in Education, 1-16. https://bit.ly/2UTAIpZ DOI: 10.1080/13603124.2019.1623923.

[18]. Heikka, J., \& Suhonen, K. (2019b). Distributed pedagogical leadership functions in Early Childhood Education settings in Finland. Southeast Asia Early Childhood Journal, 8 (2),43-56. https://bit.ly/39nJku3

[19]. Heikka, J. (2014). Distributed Pedagogical Leadership in Early Childhood Education (Academic Dissertation). Tampere University Press, School of Education, University of Tampere. https://bit.ly/3aq0isZ

[20]. Heikka, J. (2013a). Enacting Distributed Pedagogical Leadership in Finland: Perceptions of Early Childhood Education Stakeholders. In E. Hujala, M. Waniganayake \& J. Rodd (Eds). (2013). Researching Leadership in Early Childhood Education. Tampere University Press. https://bit.ly/39o84SN

[21]. Heikka， J.， \&Waniganayake, M. (2013b). Early Childhood Leadership through the Lens of Distributed Leadership. European Early Childhood Education Research Journal, 21(4), 568-580. https://bit.ly/3bzV2TL

[22]. Heikka, J., Waniganayake, M., \& Hujala, E. (2012a). Contextualizing Distributed Leadership Within Early Childhood Education: Research Evidence, Challenges and Future Research. Educational Management Administration and Leadership, 41(1), 30-44. https://bit.ly/39tq1j9

[23]. Heikka, J., \& Wanaganayake, M. (2012b). Distribution of leadership among ECE Leaders and Members of Municipal Committees in Finland. International Journal of Early Childhood Education and Care.

[24]. Heikka, J., \& Waniganayake, M. (2011). Pedagogical Leadership from a Distributed Leadership Perspective within the Context of Early Childhood Education. International Journal of Leadership in Education, 14(4), 499-512. 
[25]. Learning Scoop. (2017). Pedagogical Leadership Empowering School Community. Learning Scope. https://bit.ly/2vTtGsB

[26]. Lee, Y. Y. (2016). Pedagogical Leadership to Support New Teachers' Growth (Master's Thesis). Department of Education, University of Jyväskylä. https://bit.ly/2WTYOn7

[27]. MacNeill, N., Cavanagh, R. F., \& Silcox, S. (2005). Pedagogic Leadership: Refocusing on Learning and Teaching. https://bit.ly/2UEtHcl

[28]. Male, T., \& Palaiologou, I. (2015). Pedagogical Leadership in the 21st Century: Evidence from the Field. Educational Management Administration and Leadership, 43(2), 214-231. https://bit.ly/2y6brkm

[29]. Male, T., \& Palaiologou, I. (2016). Pedagogical Leadership in Action: Two Case Studies in English Schools. International Journal of Leadership in Education, 1-27. https://bit.ly/3dxOgzD

[30]. Male, T., \& Palaiologou, I. (2012). Learning-Centered Leadership or Pedagogical Leadership? An Alternative Approach to Leadership in Education contexts. International Journal of Leadership in Education, 15(1), 107-118.

[31]. Martinez, I. G., \& Tadeu, P. (2018a). The Impact of Pedagogical Leadership on Pedagogical Coordination in Secondary Schools. Research in Social Sciences and Technology, 3, (3), 1-15. https://bit.ly/3dBq8vY

[32]. Martinez, I. G., Jimenez, J. L. U., Burgoz, J. L., \& Tadeu, P. (2018b). The Pedagogical Leadership of the Mathematics Faculty: A Systematic Review. Education Sciences, 8(217), 1-9. DOI: 10.3390/educsci8040217.

[33]. Modise, M. R. (2019). Pedagogical Leadership in Early Childhood Development: A Means for Quality Practices through Professional Training. Glocal Education in Practice: Teaching, Researching, and Citizenship BCES Conference Books. Bulgarian Comparative Education Society. https://bit.ly/2wPPohJ

[34]. Muray, J., \& Clark, R. M. (2013). Reframing Leadership as a Participative Pedagogy: The Working Theories of Early Years Professionals. Early Years, 33(3), 289-301. DOI:10.1080/09575146.2013781135

[35]. Peng, D., \& Vašt’atková, J. P. (2016). Headteacher as pedagogical leader in pedagogical leadership in schools. GRANT journal, 5 (2), 58-60. https://bit.ly/39ngjyv

[36]. Semann, A. (2019). Pedagogical Leadership. Interrogating self in order to lead others. In S. Cheeseman \& Walker (eds.). Pedagogies for leading practice, pp. 51-64, London: Routledge.

[37]. Sergiovanni, T. J. (1998, 2006). Leadership as pedagogy, capital development and school effectiveness. International Journal of Leadership in Education, 1(1), 37-46. https://bit.ly/2UKpX9n DOI: $10.1080 / 1360312980010104$

[38]. Sweet, M., \& Moynihan, R. (2007). Improving Population Health: the uses of systematic review. Millbank Memorial Fund. www.milbanj.org
[39]. Tornsen, M. (2009). Successful Principal Leadership: Prerequisites, Processes and Outcomes. UMEA University. https://bit.ly/3bAa0co

Woodrow, C., \& Busch, G. (2009). Repositioning Early Childhood Leadership as Action and Activism. European Early Childhood Education Research Journal, 16(1), 83-93. DOI:10.1080/13502930801897053 